\title{
The time course of sense creation
}

\author{
RICHARD J. GERRIG \\ Yale University, New Haven, Connecticut
}

\begin{abstract}
In everyday conversation listeners often need to create new meanings for old words. For example, listeners must create the meaning "uniformed police officers" for the word uniforms in the utterance, "There are 20,000 uniforms in this city." For such meanings, the process of sense creation must operate to supplement ordinary sense selection. The present experiments contrast two models of the time course of these processes. The error recovery model suggests that sense creation operates only after sense selection fails. The concurrent processing model suggests that sense selection and sense creation operate simultaneously. Preempting innovations-novel terms identical in form to conventional terms, such as uniforms-provide the means to contrast the models. The experiments demonstrate that the concurrent processing model gives a more accurate description of comprehension.
\end{abstract}

Late one evening on the "Tonight Show," a guest advised Johnny Carson, "You should avoid marrying a sheep at all costs." ' Carson's guest was not warning him to avoid four-legged sheep, but rather an individual born in the Chinese year of the sheep. This novel meaning was evident from the prior discussion: The guest spent several minutes discriminating the birth years (e.g., rabbit, dragon) that would ensure good marital partners for Carson. Finally, Carson was counseled to avoid a sheep.

Sheep is an example of a contextual expression: a word or phrase whose meaning depends on the context in which it is embedded (E. V. Clark \& H. H. Clark, 1979; H. H. Clark, 1983). Because potential contexts are unlimited, contextual expressions have an unlimited number of potential meanings. Thus, this one new meaning for sheep is far from unique. Consider, for example, an art critic who could identify two current schools of painters: women who paint sheep and women who paint unicorns. The critic may suggest that Carson should avoid marrying women from the school that paints sheep. Speakers of all ages produce a variety of contextual expressions (E. V. Clark, 1981, 1982; E. V. Clark \& H. H. Clark, 1979; E. V. Clark \& Hecht, 1982; H. H. Clark, 1983; H. H. Clark \& Gerrig, 1983).

Contextual expressions mandate a different type of meaning recovery from that assumed by most theories of

Preparation of this article was supported in part by Grant MH-20021 from the National Institute of Mental Health, by a National Science Foundation Graduate Fellowship, and by Grant BRSG SO7RR07015 from the Biomedical Research Grant Program, Division of Research Resources, National Institutes of Health. I thank Herbert $H$. Clark for invaluable assistance in every phase of this project. I also am grateful to Barbara Tversky, Eve V. Clark, and Roger N. Shepard for helpful discussions on the execution and presentation of these experiments; to Ewart A. C. Thomas for statistical advice; and to Alice F. Healy, Gregory L. Murphy, and Arthur G. Samuel for comments on earlier drafts of this article. Requests for reprints should be sent to Richard J. Gerrig, Department of Psychology, Yale University, P.O. Box 11A Yale Station, New Haven, CT 06520-7447. understanding. Typically, such theories suggest that (1) all possible senses for each word in an utterance are listed in the mental lexicon, and (2) listeners select among these senses to understand a word (see, e.g., Forster, 1976, 1979; Marslen-Wilson \& Tyler, 1980; Seidenberg, Tanenhaus, Leiman, \& Bienkowski, 1982; Simpson, 1981; Simpson \& Burgess, 1985; Swinney, 1979). Contextual expressions suggest that sense creation must exist alongside sense selection as a method of meaning recovery (H. H. Clark \& Gerrig, 1983). The contextually appropriate innovative sense of sheep cannot be selected from some short list of potential meanings, because potential innovative meanings for sheep are unlimited. Instead, a comprehender must access from memory information about the conventional term sheep to create a meaning for the innovative term sheep.

The goal of this paper is to expose some properties of the time course of this process of creation. I contrast two models of meaning creation by exploiting the class of contextual expressions of which sheep is a member. In the example, the innovation sheep is particularly pernicious because there is no hint within the sentence that the word is not being used in its conventional sense. Such preempting innovations are relatively common. For example, we hear such utterances as "The ham sandwich is sitting at table 20" (the man eating the ham sandwich; Nunberg, 1979) and "[How can they] cut off a man's legs?" (the legs of a man's desk). (Further examples, along with glosses and sources, are given in the Appendix.) For innovations such as sheep, there are conventional meanings that must be situationally disregarded. With what time course are these conventional meanings preempted?

One answer is that sense selection is always attempted first, so that sense creation requires error recovery. Forster (1979) provided the foundation for such an error recovery model. He partitioned language comprehension into three separate and ordered processors: the lexical processor, responsible for recovery of entries from the lexicon; the syntactic processor, responsible for assign- 
ing grammatical structure to an utterance based on lexical information; and the message processor, responsible for bringing contextual information to bear on the representation from the syntactic processor.

This architecture mandates that sense selection precedes sense creation. Consider the utterance "Send him home with a couple of uniforms," meaning "Send him home with a couple of officers wearing uniforms." In Forster's (1979) theory, the lexical processor accesses the conventional meaning of uniform: "a formal suit of clothing." The syntactic processor then can assimilate that reading into the grammatical structure of the sentence. The mismatch of meaning and situation is not detected until the message processor brings contextual information into play. Only then can the listener construct an appropriate reading of uniforms. The language processor adopted the conventional reading of uniforms in error. Sense creation is initiated only when sufficient evidence has been gathered to rule out the conventional reading.

An alternative would be to imagine sense selection and sense creation as operating simultaneously, as concurrent processes. The context in which "Send him home with a couple of uniforms" appeared made it clear that the statement would be about police officers. Sense creation could bring the expectation, "a type of police officer," to bear on the interpretation of uniforms. Through concurrent processing, the comprehender could construct the correct innovative reading at the same time he/she rejects the incorrect innovative reading.

We might favor concurrent processing over error recovery because of evidence from other types of nonconventional language. In several domains, the creation of meaning goes on alongside the selection of meaning (see Gibbs, 1984, for a review). For example, researchers on metaphor comprehension have contrasted models analogous to the error recovery and concurrent processing alternatives. Consider the metaphorical sentence, "The train followed the parallel ribbons." One potential time course for the comprehension of this sentence would be that a reader first tries to make sense of this sentence as a literal utterance, but when this attempt fails, initiates the search for a nonliteral interpretation-error recovery (Grice, 1975, 1978; Searle, 1975, 1979). Experimentation, however, supports a concurrent processing model. Studies suggest that appropriate context eliminates the need for a solo examination of literal meaning. Contextual expectations drive the recovery of a metaphorical reading at the same time the literal reading is being rejected (Gerrig \& Healy, 1983; Ortony, Schallert, Reynolds, \& Antos, 1978). Only when context is unavailable do comprehenders display error recovery.

Concurrent processing refers to a class of processing models that describe situations of competition between two or more linguistic hypotheses (e.g., MacWhinney, Bates, \& Kliegl, 1984; MacWhinney, Pleh, \& Bates, 1985; Thibadeau, Just, \& Carpenter, 1982). Here, the competition is between the conventional and innovative meanings. Rather than waiting for sufficient evidence to dis- favor the conventional meaning, the language processor concurrently collects evidence to favor both meanings. The present experiments were designed to compare error recovery with a generic concurrent processing model, rather than to decide among versions of that model.

Four experiments were designed to contrast the views of sense creation as error recovery and concurrent processing. In each experiment, participants read short stories that established preempting meanings for old words. The first two experiments used preempting innovations based on pairs of compound nouns (Experiment 1) and agentives (Experiment 2) to test reading time predictions of the two models of sense creation. Experiment 3 examined the assumption that conventional information interferes with the construction of innovative meanings. Experiment 4 examined the moment-by-moment course of comprehension for units of text smaller than entire sentences.

\section{EXPERIMENT 1}

This experiment was designed to test the predictions of the error recovery and concurrent processing models by comparing reading time differences for sentences with conventional or innovative uses of matched pairs of compound nouns. Consider the uses of foot race in the final sentences of the following pair of stories:

The people of Marni, France have an unusual celebration every year. Over four hundred years ago, Louis $\mathrm{X}$ visited their town. He started the tradition of having annual sports events. The town's teenagers race on foot all the way around the town. The older sportsmen race horses around the same course. The foot race is the more popular event.

Over four hundred years ago, Louis $\mathrm{X}$ visited the town of Marni, France. He started the tradition of racing snails in the town square. The townspeople still gather every year for races of two lengths. By tradition, the short course is made just as long as King Louis's foot. The longer race is made the length of Louis's favorite horse. The foot race is the more popular event.

In the first story, foot race is used in its conventional sense to mean "a race on foot." In the second story, it is given the innovative meaning "a race the length of King Louis's foot." Each story can also conclude with the sentence, "The horse race is the more popular event," and a reader will recover the meanings "a race on horse" or "a race the length of King Louis's horse." In Experiment 1, each participant was asked to read one of the four versions of this story. The error recovery and concurrent processing models predict different patterns of reading times across the four versions of the story. (This methodology parallels that used in earlier evaluations of error recovery models [see Gibbs, 1984, for a review]. In those experiments, identical sentences are also given different meanings based on preceding context.)

I derived predictions from the two models based on two background assumptions. First, I assumed that, in anal- 
ogy to other idiomatic phrases, the conventional meanings for the compound nouns are stored in the internal lexicon (Gibbs, 1980; Swinney \& Cutler, 1979). Second, I assumed that the reader creates preempting readings by accessing information embodied in the representation of the story context. The error recovery and concurrent processing models diverge with respect to the time course with which this information is put to use.

The error recovery model predicts that reading times for the innovative sentences parallel those for the conventional sentences. Once readers have discovered that the conventional meanings for foot race and horse race are not intended in the innovative stories, they must reject those meanings and create new ones. Following the logic set out by Sternberg $(1966,1969)$, overall processing time should equal the sum of the time to consider and reject the conventional meaning and the time to create the innovative meaning. If context is equally supportive, it should take roughly the same amount of time to create the innovative readings for both of the compound nouns. Thus, whatever reading time differences exist for the conventional uses of the pairs of compound nouns should be more or less preserved in the innovative uses. If foot race is understood more swiftly in its conventional use, it should be understood more swiftly in its innovative use as well. This prediction of the error recovery model extends suggestions made with respect to sentence processing (e.g., Searle, 1979) down to the level of the word.

The concurrent processing model makes weaker predictions about the pattern of reading times, but they contrast nonetheless. Because sense selection and sense creation go on simultaneously, the reading times for both compounds should be roughly the same in the innovative case, irrespective of which took longer in its conventional use. Thus, the concurrent processing model makes the relatively weak claim that the reading times for the innovative uses will be unrelated to those for the conventional uses.

Participants in Experiment 1 read a series of short stories. After each story, they judged as true or false a paraphrase of the story's final sentence, the sentence that contained the target compound noun. This paraphrase judgment ensured that the readers had correctly understood the innovations.

\section{Method}

Subjects. Twenty-eight Stanford undergraduates participated for course credit. Eight subjects were excluded from further analyses because they had error rates of at least $25 \%$ (see the discussion of the error data in the Results section). Each student was tested individually. Participants in all the experiments were native speakers of English.

Materials. Twenty pairs of compound nouns were found that both had well-established conventional senses and allowed for innovative senses. Each pair, such as snow ball/fire ball and door man/cave man, had identical head nouns. The pairs of compounds were embedded in target sentences that were identical for both the conventional and innovative uses (see Table 1). A conventional context story and an innovative context story were written for each target sentence. Twenty filler stories and 5 practice stories also were con-
Table 1

Sample Stories from Experiment 1

Compound Noun Pair: fire ball/snow ball

\section{Innovative Story}

The town of Chicopee sponsors two formal dress balls each year. One of these balls commemorates a fire that almost destroyed the town. The other is in honor of a record setting snow fall some years back. Unfortunately, at the last of these balls a big fight broke out. The town fathers are quite concerned that this might happen again. The mayor is extremely worried about the approaching fire ball/snow ball.

\section{Paraphrase}

The mayor is worried about the ball held in honor of the big fire/snow.

\section{Conventional Story}

The town of Chicopee, at the foot of Mt. Erma, is in great danger. Two natural disasters are simultaneously affecting the little town. A huge ball of snow is rolling toward Chicopee from the peak of Mt. Erma. Meanwhile, the timber below the snow line has caught on fire. Chicopee's leaders fear that a ball of fire is traveling toward the town. The mayor is extremely worried about the approaching fire ball/snow ball.

\section{Paraphrase}

The mayor is worried about the big ball of fire/snow coming into town.

\section{Compound Noun Pair: door man/cave man}

\section{Innovative Story}

The Fine Arts Department was hiring a new faculty member. The department needed people in two areas. They no longer had faculty who taught about caves or doors. Unfortunately they could afford only one new professor. Professor Rogers had an opinion about the best choice. He said, "We really ought to get the door man/cave man."

\section{Paraphrase}

A faculty member to teach about doors/caves is needed.

\section{Conventional Story}

A movie company is making a new multimillion dollar film. This afternoon they are supposed to film a strange dream sequence. At the beginning, a Neanderthal man is seen standing by a cave. Suddenly, he becomes the man guarding the door of a posh hotel. The director realized that no one had been hired to play this part. He said, "We really ought to get the door man/cave man."

\section{Paraphrase}

An actor to play the man by the door/cave is needed.

structed. These stories were similar in tone and content to the experimental stories but contained no innovations. (Table 2 provides examples of the filler stories.)

Each target compound appeared in the final sentence of the sixsentence stories. After each story, a seventh sentence was presented that was a possible paraphrase of the sentence containing the compound noun. The conventional and innovative stories required different paraphrase sentences. For all the innovative sentences, the paraphrase sentence included the two nouns of the compound (e.g., "The horse race is the more popular event" was paraphrased as "The townspeople prefer the race that is the length of a horse"), but this was not always possible for the conventional uses because some were too idiomatic (e.g., fire fly could not easily be paraphrased in terms of fire and $f l y)$.

Apparatus. The experiment was controlled by a PDP-11/34 computer that measured and recorded reading times. The participants sat in front of a Hazeltine $1500 \mathrm{CRT}$ terminal with their hands resting on the keyboard. The sentences were displayed in the center of the screen in standard upper- and lowercase type.

Design. Four lists of stories were constructed so that each story appeared in a different version (two compound nouns in two contexts) on each list. Each list contained 10 compound nouns used in innovative contexts and 10 used in conventional contexts. The 
Table 2

Sample Filler Stories

Karl was a great fan of every sort of modern art. The walls of his apartment were covered with abstract paintings. He was especially fond of paintings with bright colors. Many of them seemed to jump off the wall and attack the viewer. Karl took great pride in showing his collection to his friends. They were often amazed at the quality of the works.

\section{Paraphrase}

Karl's friends were surprised that his collection was so ugly

The circus was in town for the first time in many years. They were advertising their arrival with a big parade. Colorfully painted floats filled the town's main street. Some floats served as cages for ferocious lions and tigers. Others carried hordes of clowns, jugglers, and acrobats. The town's children were most amazed by the huge elephants.

\section{Paraphrase}

The elephants were the sight that amazed the children least.

order of stories was the same in each list so that every participant saw one of the four versions of a given story at the same relative position in the experimental session. This order was randomly determined. The 20 filler stories were also randomized and identically positioned within the lists of experimental stories.

The paraphrase sentence was true for all of the experimental stories and false for all of the filler stories, so equal numbers of true and false responses were required overall. (Examples of false paraphrases are given for the stories in Table 2.)

Procedure. The participant was instructed that he/she would read brief stories and then judge a paraphrase of the final sentence of each story as true or false. Each story was preceded by the prompt "PUSH BUTTON FOR NEXT STORY."' When the student pushed the character " $a$ " on the keyboard, the screen became blank for $200 \mathrm{msec}$, and then a fixation cross $(+)$ occurred at the first character position for $750 \mathrm{msec}$. After a second delay of $250 \mathrm{msec}$, the first sentence of the story appeared on the screen. When the reader pushed the " $a$ " again to indicate that the sentence had been understood, a new sentence appeared immediately. This procedure continued throughout the story. After the sixth sentence, the student heard a beep from the terminal, and then the paraphrase sentence appeared. "True" and "false" were indicated by pressing either the " 9 " or the " 0 " on the keyboard. The labeling of these keys as "true" and "false" was counterbalanced across subjects. This sequence of a story followed by a paraphrase judgment was repeated for the 5 stories in the practice session (none contained innovations; three were true and two false) and for the 40 stories in the experimental session.

\section{Results and Discussion}

Only reading times for stories on which participants made correct paraphrase judgments were used in the analyses. In addition, the distribution of judgment times was examined, and data that fell beyond a clear gap in the histogram were eliminated. Overall, these procedures resulted in a loss of $13.5 \%$ of the data $(11.5 \%$ and $2 \%$, respectively; the 8 excluded subjects averaged $32 \%$ errors).

On average, the readers took $2.31 \mathrm{sec}$ to understand the conventional uses and $2.73 \mathrm{sec}$ to understand the innovative uses of the compound nouns $\left[\min F^{\prime}(1,32)=\right.$ $5.41, p=.027]$. (There were no reliable differences between the conventional and innovative uses on paraphrase judgment times or error rates.) Fortunately, the inclusion of the matched pairs of compound nouns allows for a more stringent test of the error recovery model than only this global comparison. The model suggests that the relationships between the reading times for the paired compound nouns should be the same for both the conventional and innovative uses. We can test that hypothesis by comparing the reading time differences-the slopes of the lines between the two members of each pair-for the two types of uses. For example, we can compare the differences between the reading times for horse race and foot race when they were used conventionally or innovatively and determine whether horse race was more slowly understood in both cases.

Thus, an initial examination of the error recovery prediction was made by testing the hypothesis that the mean difference for the innovative uses was identical to that for the conventional uses. However, these slopes were found to be reliably different $\left[\min F^{\prime}(1,36)=7.27\right.$, $p=.011]$, which contradicts the error recovery model.

Two tests were performed to examine the stronger possibility that these slopes were inversely related. First, a sign test was done on the product of the slopes to test the null hypothesis that the direction of the difference would be the same for the conventional and innovative uses. These products would be positive if the differences were in the same direction and negative if the differences were in opposite directions. Of 20 comparisons for the innovative uses of the items, 14 showed negative products, 2 were tied (products less than $20 \mathrm{msec}$ ), and 4 showed positive products $(p<.02)$. A $t$ test also showed the products to be reliably negative $[t(19)=2.10, S E M=$ $0.10, p<.05]$, reinforcing the conclusion from the sign test.

This inversion of slopes was made manifest by determining which member of the pairs such as horsse race and foot race readers had understood more quickly. This compound noun was labeled fast, and its partner slow. The reading times for the innovative sentences were then arranged to parallel the conventional pattern. That is, if "The foot race is the more popular event" took less time to read in its conventional use, then that sentence was called fast in its innovative use as well. Table 3 presents the rearranged reading time data. (Note that none of the statistics performed on the items depend on this rearrangement.) With this arrangement of the data, it can be seen that reading times for the conventional and innovative uses of the slow compound nouns converge. For those compound nouns, the processing difficulty was equivalent for the conventional and innovative uses.

The results for subjects parallel those for items. The reading time differences for the conventional and innovative uses were opposite in direction in both the nonparametric (sign test: 14 different, 5 same, 1 tie, $p=.032$ ) and parametric $[t(19)=2.50, S E M=0.10, p=.022]$ analyses. The tests across subjects and items converge on the same conclusion: The compound nouns that took less time to read when used conventionally took longer to read when used as innovations. If "The foot race is the more popular event" took less time to understand when foot race and horse race were used conventionally, it took more time to understand when they were used innovatively. 
Table 3

Reading Times, Error Rates, and Paraphrase Judgment Times for Target Sentences in Experiment 1

\begin{tabular}{lccc}
\multicolumn{1}{c}{ Sentence Type } & Reading Times & Error Rate & $\begin{array}{c}\text { Paraphrase } \\
\text { Judgment Time }\end{array}$ \\
\hline Conventional, Fast & 2.10 & 10.00 & 3.71 \\
Conventional, Slow & 2.53 & 15.00 & 3.79 \\
Innovative, Fast & 2.97 & 18.00 & 4.00 \\
Innovative, Slow & 2.51 & 11.00 & 3.83 \\
\hline
\end{tabular}

Note-Fast and slow refer to reading times for the conventional uses. Reading times and paraphrase judgment times are given in seconds. Error rates are the percentage out of 100 responses.

Table 3 also presents the error rates and paraphrase judgment times for Experiment 1. Although there were no reliable differences among these measures, they show the same general pattern as the reading times. The compound nouns that were easier to verify correctly or quickly when used conventionally were harder when used innovatively. There is no evidence of an equalizing spillover of processing into the paraphrase judgments or of a speedaccuracy tradeoff.

The error rates ( $13.5 \%$ overall) would have been higher if subjects who made substantial numbers of errors had not been eliminated from the analyses. The failure of these subjects to understand the innovations could arise from at least two sources. These subjects may not have been reading the stories very carefully, so that they failed to create the correct context in which to interpret the innovation. (In fact, many of the subjects who were omitted were blatant in their lack of seriousness during the experimental session.) Alternatively, some subjects may have had a strong bias toward conventional interpretation, whatever the dictates of context. The experiments presented here were not designed to differentiate between motivational and dispositional accounts of high error rates.

One possible alternative explanation for the readingtime results could be that the different innovative meanings of, for example, foot race and horse race were differentially predicted by the story contexts such that the apparent inversion in reading times would be only coincidental. To rule out this possibility, 20 Yale undergraduates read the innovative stories with the original paraphrase sentences serving as targets. ${ }^{1}$ For example, in the first example from Table 1, they read the story ending with one version of "The mayor is extremely worried about the approaching ball held in honor of the big fire/snow" rather than "The mayor is extremely worried about the approaching fire ball/snow ball." The reading times for the sentences that were paraphrases of the fast compound nouns $(2.71 \mathrm{sec})$ did not differ from those for the slow compound nouns $(2.63 \mathrm{sec})$ [subjects, $F(1,18)$ $=0.11, M S_{\mathrm{e}}=0.12, p>.10$; items, $F(1,18)=1.12$, $\left.M S_{\mathrm{e}}=0.07, p>.10\right]$. This control experiment rules out the possibility that the pattern of data for the innovative compound nouns was completely due to differential predictability from context.
The results of this experiment contradict the predictions of the error recovery model. This contradiction, however, presupposes that the reading time differences for the conventional uses of the compound nouns reflect real differences in the accessibility of their meanings, and not simply differential fit in the story contexts. To verify this assumption, 20 psychology graduate students at Yale University were paid to perform a ratings task. They read one version of each of the 20 experimental stories and rated how well each final sentence fit in the context of the preceding sentences on a 7-point scale ranging from fits poorly with context to fits excellently with context. Table 4 presents the goodness-of-contextual-fit ratings. In the global analysis of variance, conventional uses were rated as marginally better fitting than innovative uses [subjects, $F(1,16)=3.62, M S_{\mathrm{e}}=0.82, p=.075$; items, $\left.F(1,16)=3.40, M S_{\mathrm{e}}=0.87, p=.084\right]$, and the slow sentences were rated as better in context in the analysis by subjects $\left[F(1,16)=4.95, M S_{\mathrm{e}}=0.32, p=.041\right.$; items, $F(1,16)=2.26, M S_{\mathrm{e}}=0.32, p>.10$ ]. The largest effect, however, was the interaction between the two factors $\left[\min F^{\prime}(1,27)=4.18, p=.051\right]$. This interaction arises because there is little difference between the goodness-of-contextual-fit ratings for the conventional uses [Newman-Keuls: subjects, $q(3,16)=1.50, M S_{\mathrm{e}}=$ $0.23, p>.10$; items, $q(3,16)=0.95, M S_{\mathrm{e}}=0.56$, $p>.10]$, whereas this difference is reliable for the innovative uses [subjects, $q(3,16)=6.10, p<.01$; items, $q(3,16)=3.88, p<.05]$.

These ratings thus suggest that differences in reading times for the conventional uses of the paired compound nouns cannot be attributed to the stories themselves. On the other hand, for the innovative uses, those that were read more slowly were reliably rated as fitting less well

Table 4

Goodness-of-Contextual-Fit Ratings for Experiment 1

\begin{tabular}{lllc}
\hline & \multicolumn{2}{c}{ Reading Time } & \\
\cline { 2 - 3 } Sentence Type & Fast & Slow & $M$ \\
\hline Conventional & 5.16 & 5.00 & 5.08 \\
Innovative & 4.37 & 5.02 & 4.70 \\
$M$ & 4.76 & 5.01 & \\
\hline
\end{tabular}

Note-Fast and slow refer to reading times for the conventional uses. Ratings ranged from 1 ( fits poorly with context) to 7 ( fits excellently with context). 
in context, despite the fact that the control experiment showed that the stories themselves predicted the innovations equally well. The grouping into fast and slow for the innovations was once again determined after the experiment, to parallel the true fast versus slow for the conventional uses. Thus, the reading times for the conventional uses distinguish which innovations raters judge as fitting well or poorly in context. An alternative explanation-that the pattern is merely coincidental-is disconfirmed further in Experiment 2.

Past research has rejected an error recovery model in several domains of language use without replacing it with any well-specified alternative. The results of Experiment 1 make a start toward such an alternative by championing one particular form of a concurrent processing model. Only this class of models suggests that the processes of sense selection and sense creation go on simultaneously. The results of Experiment 1 suggest that this general account is correct, but that the presence of two simultaneous processes retards an understander's efforts. Theorists have suggested that people have finite processing resources that are distributed among the tasks they must perform (see Kahneman, 1973; Norman \& Bobrow, 1975; Posner \& Boies, 1971). According to an elaborated concurrent processing model, when readers understand preempting innovations, they are dividing their resources between the processes of examining a conventional reading and creating an innovative meaning. The greater the demands of the conventional reading, the fewer resources remain for constructing the innovative meaning. If a conventional meaning is highly accessible, resources are divided between two processes-sense selection and sense creation-for a lengthy period of time. The processor's relatively prolonged period of divided resources lead to a long latency for creating an innovative meaning. If we assume that fast access of the conventional meaning underlies fast conventional reading times and that slow access underlies slow reading times, then this model would predict the results of Experiment 1. This reasoning suggests that the latency for understanding a preempting innovation should vary continuously with conventional reading time. Experiment 3 tested that hypothesis. First, Experiment 2 presented a replication of the results of Experiment 1 with a different type of preempting innovation.

\section{EXPERIMENT 2}

Experiment 2 replicated Experiment 1 with innovations based on derived agentives. Many English words for people who perform activities are derived by appending the suffix -er to a noun or verb: a farmer, a trumpeter, $a$ dreamer. These agentives can also be given innovative meanings. Consider this pair of stories:

Gary looked out his back window into the next yard. He saw his neighbor, John Porter, hard at work. John was starting to turn over a large patch of earth. Gary called out, "What are you doing back there, John?', John answered, "My wife wants me to grow fresh vegetables. She's trying to turn me into a farmer."
John and his wife both paint as a hobby. John likes to sit indoors and paint elaborate still-lifes. His wife likes to be outdoors painting gardens and farms. John told a friend that his wife wants him to change. John explained, "She wants us to paint the same things. She's trying to turn me into a farmer."

In the first story, farmer is used in its conventional sense to mean "someone who farms." In the second story, it is given the innovative meaning "someone who paints pictures of farms." "Each story can also be concluded with the sentence, "She's trying to turn me into a gardener."

The design of Experiment 2 was identical to that of Experiment 1 . Conventional and innovative stories were written that used matched pairs of agentives in identical target sentences. Participants were required to read these stories and make paraphrase judgments on the target sentences.

\section{Method}

Subjects. Twenty-four Stanford undergraduates participated in the experiment. Four of these subjects were excluded from further analyses because of high error rates. Each student was tested individually and received $1 \mathrm{~h}$ of experimental credit for completing this and one other short experiment.

Materials. Sixteen pairs of agentives were found that had wellestablished conventional senses and allowed for innovative senses. The pairs of agentives were embedded in target sentences that were identical for both the conventional and innovative uses. Table 5 presents the full stories for the pairs bugler/trumpeter and doodler/dreamer. The same 20 filler stories and 5 practice stories from Experiment 1 were used. As in Experiment 1, each story was followed by a paraphrase of the target sentence.

Apparatus. The experiment was controlled by an Apple II+ microcomputer. The students sat in front of a Setchell Carlson video monitor with their hands resting on a button box. The button box had a row of seven buttons. The left-hand button was labeled "NEXT," and the fourth and fifth buttons were labeled "TRUE" and "FALSE" randomly across participants. Each sentence was displayed in the center of the screen in standard upper- and lowercase type.

Design. The design was identical to Experiment 1 but with only 16 experimental stories, so each list contained 8 agentives in conventional contexts and 8 in innovative contexts.

Procedure. The procedure of Experiment 2 differed from that of Experiment 1 only in the use of a button box rather than CRT terminal keys to serve the "next," "true," and "false" functions.

\section{Results and Discussion}

Table 6 presents the reading times, error rates, and paraphrase judgment times for Experiment 2. Reading times from stories on which readers made errors (13.75\%) and on which judgment times fell outside the distribution $(1.25 \%)$ were discarded (excluded subjects averaged $34 \%$ errors). The data revealed a consistent difference between the conventional and innovative uses of the agentives. Sentences with conventional agentives were understood faster in both component analyses $(2.97 \mathrm{sec}$ vs. $3.60 \mathrm{sec})$ [items, $F(1,16)=5.49, M S_{\mathrm{e}}=1.41, p=.033$; subjects, $F(1,15)$ $\left.=5.55, M S_{\mathrm{e}}=1.31, p=.032\right]$. Fewer errors were made in their verification $(5 \%$ vs. $25 \%)\left[\min F^{\prime}(1,23)=\right.$ $9.89, p<.005$ ), and they were verified more swiftly in the subject analysis $(4.82 \mathrm{sec}$ vs. $5.40 \mathrm{sec})$ [subjects, 
Table 5

Sample Stories from Experiment 2

Agentive Pair: bugler/trumpeter

Innovative Story

Paul runs the busiest instrument repair shop in town. Whenever someone has a problem they go right to him. Paul is especially good with brass instruments. He can repair all sorts of trumpets and bugles. Many symphony players ask him to repair their instruments. There are few buglers/trumpeters as good as Paul.

Paraphrase

There are few people who can repair a bugle/trumpet so well.

\section{Conventional Story}

Paul's friends believed that he was born to be a musician. People were amazed by the beauty of his trumpet playing. Lately, Paul was bored of playing only one instrument. He decided it would be fun to play the bugle as well. Paul's skill on the bugle soon equalled that on the trumpet. There are few buglers/trumpeters as good as Paul.

Paraphrase

There are few people who can play the bugle/trumpet so well.

Agentive Pair: doodler/dreamer

Innovative Story

Karen Overson was trained as a psychotherapist. She had spent several years deciding which theory to adhere to. One theory put great weight on interpreting patients' dreams. Another put emphasis on the doodles that people draw. Karen's friend wanted to know which theory she had selected. Karen said, "I'm a dedicated doodler/dreamer."

Paraphrase

Karen said that she interprets people's doodles/dreams.

\section{Conventional Story}

Karen had terrible problems paying attention in lectures. She tried to listen to her professors but to no avail. Her mind would wander and she would start to daydream. Sometimes she would devote her energies to elaborate doodles. Her friend, Chuck, kidded her about her inattention in class. Karen said, "I'm a dedicated doodler/dreamer."

\section{Paraphrase}

Karen said that she spent time doodling/dreaming.

$F(1,15)=4.81, M S_{\mathrm{e}}=3.32, p=.044$; items, $F(1,15)$ $\left.=1.33, M S_{e}=4.36, p>.10\right]$.

The data in Table 6 are arranged according to the same scheme as those in Experiment 1 so that the pattern of inverted reading times is made manifest. (As in Experiment 1 , an initial analysis determined which member of the pairs such as gardener and farmer had taken less time to understand in their conventional uses. The innovative uses then were rearranged to parallel the conventional pattern.) The table reveals that the data of Experiment 2 fall into the same qualitative pattern as those from Experi- ment 1 . The quantitative evidence is less conclusive. In Experiment 1, we were able to rule out the error recovery prediction that the reading time differences would be the same for the conventional and innovative uses. In Experiment 2 , the slopes of the reading time differences differ only across items [items, $t(1,15)=2.47, S E M=$ $0.30, p=.026$; subjects, $t(1,15)<1, S E M=0.33$ ] Also, there was no statistical support for the qualitative inversion of these slopes (all sign tests and $t$ values are nonsignificant).

Although none of the interactions are significant, the paraphrase time and error rates-like the reading timesare qualitatively consistent with Experiment 1 . The paraphrase times parallel the reading times, as do the error rates for the innovative uses. These data weakly, but consistently, argue against the error recovery model.

A control study identical to that for Experiment 1 was conducted to ensure that the stories did not differentially predict the innovative uses. For this experiment, there was a trend in the control reading times in the direction opposite the experimental effect. Paraphrases of the fast innovations were read in $2.23 \mathrm{sec}$, and paraphrases of the slow innovations in $2.49 \mathrm{sec}$ [items, $F(1,14)=4.32, M S_{\mathrm{e}}=$ $0.10, p=.057$; subjects, $F(1,18)=1.56, M S_{\mathrm{e}}=0.22$, $p>.10]$. The experimental difference between fast and slow was $-290 \mathrm{msec}$. This control difference is $260 \mathrm{msec}$. The control experiment suggests that the result of Experiment 2 might have been stronger had the stories been equally predictive of the two innovations.

Table 7 presents the goodness-of-contextual-fit ratings. The same 20 graduate students from Experiment 1 made these ratings. In the overall analysis, the conventional sentences were rated as reliably better in context than the innovative sentences $\left[\min F^{\prime}(1,19)=23.40, p<.0001\right]$. Another explanation for the relatively weaker effects of Experiment 2 might, thus, be that the innovative agentives in this experiment were less well supported in context than were the innovative compounds in Experiment 1. The fast/slow comparison was reliable in both component analyses [subjects, $F(1,16)=4.69, M S_{\mathrm{e}}=0.42$, $p<.05$; items, $F(1,12)=6.12, M S_{\mathrm{e}}=0.26, p<.03$ ] The interaction of these two factors was marginal in both analyses [subjects, $F(1,16)=3.30, M S_{\mathrm{e}}=0.34$, $p=.088$; items, $F(1,12)=3.21, M S_{\mathrm{e}}=0.28$, $p=.098)$. The specific comparisons parallel those of Experiment 1 . There was no reliable difference between rat-

Table 6

Reading Times, Error Rates, and Paraphrase Judgment Times for Target Sentences in Experiment 2

\begin{tabular}{lccc}
\hline Sentence Type & Reading Times & Error Rate & $\begin{array}{c}\text { Paraphrase } \\
\text { Judgment Time }\end{array}$ \\
\hline Conventional, Fast & 2.63 & 6.24 & 4.75 \\
Conventional, Slow & 3.30 & 3.76 & 4.89 \\
Innovative, Fast & 3.75 & 28.76 & 5.71 \\
Innovative, Slow & 3.46 & 21.24 & 5.10 \\
\hline
\end{tabular}

Note-Fast and slow refer to reading times for the conventional uses. Reading times and paraphrase judgment times are given in seconds. Error rates are the percentage out of 80 responses. 
Table 7

Goodness-of-Contextual-Fit Ratings for Experiment 2

\begin{tabular}{lllc}
\hline & \multicolumn{2}{c}{ Reading Time } & \\
\cline { 2 - 3 } Sentence Type & Fast & Slow & $M$ \\
\hline Conventional & 5.32 & 5.40 & 5.36 \\
Innovative & 3.21 & 3.76 & 3.48 \\
$M$ & 4.26 & 4.58 & \\
\hline
\end{tabular}

Note-Fast and slow refer to reading times for the conventional uses. Ratings ranged from 1 (fits poorly with context) to 7 (fits excellently with context).

ings for the conventional pairs [Newman-Keuls: subjects, $q(2,16)=.61, p>.10$; items, $q(2,12)=.60, p>.10 \mathrm{~J}$. This difference for innovative pairs was reliable [subjects, $q(2,16)=4.20, p<.01$; items, $q(2,12)=4.15$, $p<.05]$. Thus, the difference in goodness-of-contextualfit ratings found for Experiment 1 is more than coincidental. Rather, it seems that the pattern of these ratings has the same underlying cause as the patterns for the other measures.

The results from Experiment 2 complement those of Experiment 1. Together, these experiments provide strong evidence against error recovery predictions. The unelaborated concurrent processing model suggests a conservative interpretation of these two experiments: meaning creation goes on alongside meaning selection, and the processing of preempting innovations is unrelated to the processing of the conventional words on which they are based. A concurrent processing model incorporating resource limitations suggests a stronger interpretation of the data: The processing of conventional and innovative uses are in competition. Although the data from Experiment 2 mandate some caution, I pursued the stronger interpretation in Experiment 3.

\section{EXPERIMENT 3}

We can best explain the results of Experiments 1 and 2 by assuming that the consideration of a conventional meaning interferes with the construction of an innovative meaning: The greater the demands a conventional hypothesis makes on processing resources, the longer it takes to create the innovative reading. In Experiment 3, I tested this assumption by relating conventional reading times to an explicit measure of interference.

Once again, short stories endowed compound nouns with preempting meanings. In each of these stories, the preempting compound was matched with a compound noun that had no conventional reading, a pure innovation. Consider the following story:

Mr. Jones decided to buy a new sled for his children. He went to the neighborhood toy store. All of the sleds had pictures of animals on them. Mr. Jones couldn't decide which picture to get. His children loved both cats and dogs.

Finally, he decided on a dog sled.

The alternative ending for this story is, "Finally, he decided on a cat sled." Readers should come to much the same interpretation of dog sled and cat sled, "a sled with a picture of a dog or cat." A second story for each pair of preempting and pure innovations served as a measure of the conventional reading time:

Mr. Jones had just moved to Alaska. He was interested in taking up the local sports. He had thought about buying some dogs to pull a sled. Glacier climbing also sounded attractive to him. He spent a long time debating about what equipment to buy. Finally, he decided on a dog sled.

The error recovery and concurrent processing models give different accounts of how cat sled must be understood. According to both models, a reader must initiate a search for lexical information, because cat sled itself provides no clue that it is an innovation. The unsuccessful search is comparable to the nonword condition of a standard lexical decision task in which a reader is given a string of letters, such as thrunk, and must judge it to be nonsense. According to Forster's (1979) theory, the prototype for the error recovery model, judgments between words and nonwords are made at an early level of the system, the lexical processor. Low-level detection of the absence of conventional information allows the construction of the innovative meaning of cat sled to be initiated with little unnecessary processing. This situation contrasts with the preempting use of dog sled for which, according to the error recovery model, the lexical, grammatical, and message processors all are employed before the conventional meaning can be rejected and the innovative meaning constructed. The error recovery model thus predicts that preempting innovations should take longer to understand than pure innovations.

The concurrent processing model suggests that the search for lexical information and the construction of an innovative meaning for cat sled go on simultaneously. Although the resources of the processing system initially must be shared between these two functions, once the absence of lexical information is detected, construction of the innovative meaning goes on alone. Thus, the pure innovations give a rough estimate of how processing proceeds when there is only brief competition for resources. However, pure innovations need not always be understood more quickly than preempting innovations. The difference depends on the rate of access of the preempting innovation's conventional base. If a conventional meaning is accessed quickly, then resources are shared at length. The preempting innovation then is slow with respect to the pure innovation. If a conventional meaning is accessed less quickly, we would expect the difference between the preempting and pure innovations to be smaller. The concurrent processing hypothesis thus suggests that shorter conventional reading times lead to a greater difference between the pure and preempting innovations.

\section{Method}

Subjects. Twenty-five Stanford undergraduates participated in the experiment. Seven of these subjects were excluded from further analyses because of high error rates. Each student was tested 
Table 8

Sample Stories from Experiment 3

\section{Compound Noun Pair: fish pond/goat pond}

\section{Innovative Story}

Roger was landscaping the Von Ritz estate. Mrs. Von Ritz had some very eccentric ideas. She requested that the hedges be trimmed to spell Von Ritz. She also gave instructions about the shapes of the artificial ponds. One pond was to look like a fish and one like a goat. Roger began work on the fish pond/goat pond.

\section{Paraphrase}

Work was begun to make the pond look like a fish/goat.

\section{Conventional Story}

Roger was fixing up the old Von Ritz estate for a new owner. He had been asked especially to clean up the old pond. The new owner was an avid sportsman and hoped to go fishing there. The water was currently too polluted for fish to survive. Old tires and beer cans would have to be removed. Roger began work on the fish pond

\section{Paraphrase}

Work was begun to make the pond suitable for fish.

\section{Compound Noun Pair: ice water/fork water}

\section{Innovative Story}

Susan and Andy were sitting next to each other at a large banquet. They kept mixing up napkins, silverware, and glasses of water. Andy had a cold so he didn't think Susan should drink from his glass. They decided they needed a system to keep their glasses apart. Susan put one near a bowl of ice and the other near a fork. Susan said, "Remember, the ice water/fork water is mine."

\section{Paraphrase}

Susan said that the water near the ice/fork is hers.

\section{Conventional Story}

Susan and Andy were cooking a big meal together. Susan was making the dessert and Andy was cooking the entree. They each had ingredients spread all over the kitchen table. Both had similar bowls that they were using for water. One bowl of water had salt in it, the other just ice. Susan said, "Remember, the ice water is mine."

\section{Paraphrase}

Susan said that the water with the ice is hers.

individually and received $1 \mathrm{~h}$ of experimental credit for completing this and one other short experiment.

Materials and Apparatus. Eighteen conventional compound nouns that afforded innovative senses were matched with purely innovative compounds. The pairs were embedded in target sentences that were identical for both the conventional and innovative uses. Table 8 presents the full stories for the pairs fish pond/goat pond and ice water/fork water. Eighteen filler stories and the five practice stories from Experiment 1 were used. As in Experiments 1 and 2 , each story was followed by a paraphrase of the target sentence.

The apparatus was identical to that in Experiment 1.

Design and Procedure. The design was identical to Experiments 1 and 2, with the exception that there were only three versions of each story. These stories were distributed to three lists so that each list contained 6 preempting innovations, 6 pure innovations, and 6 conventional uses. These 18 experimental stories were randomly intermixed with the 18 filler stories. The random order was identical for all participants.

The procedure was identical to that of Experiment 1.

\section{Results and Discussion}

Reading times from stories on which readers made errors $(9.9 \%)$ and on which judgment times fell outside of the distribution (1.2\%) were discarded (excluded subjects averaged $33 \%$ errors). Table 9 presents the reading times, error rates, and paraphrase judgment times for the three versions of each target sentence. Analyses of variance of these data revealed a reliable increasing trend from conventional uses, to pure innovations, to preempting innovations $\left[\min F^{\prime}(2,58)=6.27, p<.004\right]$. Newman-Keuls comparisons were made to examine the reliability of the pairwise differences. Conventional uses took less time to read than both preempting innovations [subjects, $q(3,30)$ $=7.41, M S_{\mathrm{e}}=0.14, p<.01$; items, $q(3,30)=6.09$, $M S_{\mathrm{e}}=0.27, p<.01$ ] and pure innovations [subjects, $q(2,30)=5.61, p<.01$; items, $q(2,30)=5.16$, $p<.01]$. However, the reading times for the pure and preempting innovations were not reliably different [subjects, $q(2,30)=1.79, p>.10$; items, $q(2,30)=1.09$, $p>$.10]. The error rates and paraphrase times did not entirely parallel the reading times, but these trends were mainly unreliable. Only one reached significance: paraphrase judgments with subjects as a random variable $\left[F(2,30)=3.66, M S_{\mathrm{e}}=0.45, p=.037\right]$. Furthermore, the error rate for pure innovations was higher than that for preempting innovations, reinforcing the conclusion that preempting innovations were not, as predicted by the error recovery model, more difficult to process than pure innovations. (The error rates and paraphrase judgment times for the conventional stories were rather high in this study, suggesting that the paraphrase sentences may have been of low quality. Because the paraphrases for the innovations were different sentences-and identical except for the substitution of one word across the two types of innovations-the poor quality of the conventional paraphrases should not have affected the interpretation of that comparison.)

For each item, a difference score between the reading time for the preempting and pure innovation was computed. The concurrent processing model suggests that these differences should be related to reading times for the conventional uses. This hypothesis was tested by partitioning the 18 items into two groups according to the

Table 9

Reading Times, Error Rates, and Paraphrase Judgment Times for Target Sentences in Experiment 3

\begin{tabular}{lccc}
\hline \multicolumn{1}{c}{ Sentence Type } & Reading Times & Error Rate & $\begin{array}{c}\text { Paraphrase } \\
\text { Judgment Time }\end{array}$ \\
\hline Conventional & 2.12 & 15.75 & 4.34 \\
Pure Innovation & 2.67 & 10.20 & 3.72 \\
Preempting Innovation & 2.83 & 6.81 & 4.15 \\
\hline
\end{tabular}

Note-Reading times and paraphrase judgment times are given in seconds. Error rates are the percentage out of 108 responses. 
sign of their difference scores. For 8 of the items, the preempting innovations took less time to understand than the pure innovations. The mean conventional reading time for those items was $2.41 \mathrm{sec}$. For the remaining 10 items, the preempting innovation took longer to read, with a mean conventional reading time of $1.89 \mathrm{sec}$. Despite the small numbers of observations in these two groups, these reading time values were reliably different $[F(1,16)=$ $\left.5.16, M S_{\mathrm{e}}=0.26, p=.035\right]$. Although this analysis is essentially correlational, the pattern is consistent with the findings of Experiments 1 and 2. When the preempting innovations were slow with respect to a paired pure innovation, conventional reading time was fast; when the preempting innovations were fast with respect to the pure innovation, conventional reading time was slow. This pattern of results favors a concurrent processing model over an error recovery model.

\section{EXPERIMENT 4}

In Experiment 4, I hoped to obtain the same pattern of reading time differences found in Experiments 1 and 2 for full sentences when times for understanding only the specific conventional or innovative word were examined. Just, Carpenter, and Woolley (1982) identified a number of reliable methods for obtaining moment-by-moment measures of processing difficulty in reading comprehension. In one of these procedures, readers are asked to advance through a text one or several words at a time (see also Aaronson \& Scarborough, 1976, 1977; Mitchell \& Green, 1978). Because of the length and number of stories in this experiment, I segmented the sentences into natural units of one to five words. For example, the target sentence of the snow ball story from Experiment 1 (see Table 1) was divided like this:

$$
\begin{aligned}
& \text { The mayor } \\
& \text { is } \\
& \text { extremely worried } \\
& \text { about the approaching } \\
& \text { snow ball. }
\end{aligned}
$$

Snow ball, or the matched compound fire ball, was isolated in all four versions of the story. This allowed for a direct comparison of the time required to understand only the conventional or only the preempting use of the compounds.

Just et al. (1982) argued that this method is reliable because "the reader pauses on each word until the relevant processes have been completed to some criterion" (p. 234), a practice they called the immediacy strategy. They suggested that the time a reader spends on each word provides an accurate estimate of all the processing a reader must perform to understand that word and to integrate it with the preceding text. When readers use the immediacy strategy, the difficulty of comprehending one segment of text does not affect the processing time for subsequent portions of text. The immediacy strategy has been contradicted in some domains of language processing (see, e.g., Ehrlich \& Rayner, 1983). In Experiment 4, I further examined the claim of immediacy for text containing one type of nonconventional language, preempting innovations. To look for a spillover of processing difficulty from one segment to the next, I compared the reading times for the portion of the sentence containing the innovation (the target measure) with the combined reading times for the target portion and very next portion (the spillover measure). For preempting innovations, there is a less direct link between reading a word and recovering its meaning than for conventional uses of words. We might expect readers to ask for the next segment of a text, because they have finished reading the current segment, before they have fully settled on the target's innovative meaning. The difficulty of understanding the innovations might lead to a violation of the immediacy strategy.

As in the past, participants in this experiment read a number of stories and performed a paraphrase judgment on the target sentence of each one.

\section{Method}

Subjects. Twenty-four Stanford undergraduates participated in the experiment. Four of these subjects were excluded from further analyses because of high error rates. Each student was tested individually and received $1 \mathrm{~h}$ of experimental credit for completing this and two other short experiments.

Materials. Each of the 20 pairs of stories from Experiment 1 were segmented into small units of one to five words. This variation in unit length was necessary so that the segments could be restricted to sensible grammatical units; that is, each sentence segment generally consisted of a noun phrase, a verb, an auxiliary and verb, or a prepositional phrase. The target compound nouns were embedded in units as small as possible within that framework. For example, many of the target units consisted of a definite article and the compound noun, such as "the horse race." If the target compound noun originally appeared in the initial segment of the final sentence of a story, the sentence was rewritten. For example, "The horse race was the more popular event" was changed to "The townspeople enjoy the horse race best of all." The practice and filler stories from Experiment 1 were also segmented and used in this experiment.

The paraphrase sentences were not segmented into phrases. Pretesting suggested that readers found these judgments difficult when the paraphrase sentence was not presented in its entirety.

Apparatus. As in Experiment 2, an Apple II+ microcomputer with an attached button box were used to conduct this experiment. The video display was an ULTRONIC Videomaster. Each participant selected a comfortable reading distance from the video display. Sentences were displayed in the center of the screen in standard upper- and lowercase type.

Design and Procedure. The design and procedure of the experiment paralleled those of the previous experiments. Participants read the stories by pressing the "NEXT" button after each sentence segment

\section{Results and Discussion}

Data from stories on which readers made errors $(9.0 \%)$ and on which judgment times fell outside of the distribution (1.5\%) were discarded (excluded subjects averaged $31 \%$ errors). Analyses were carried out on two different reading time measures. One measure included only the reading times for the sentence segments containing the target compound (the target measure). The second mea- 
Table 10

\begin{tabular}{|c|c|c|c|c|}
\hline Sentence Type & $\begin{array}{c}\text { Target } \\
\text { Reading } \\
\text { Times }\end{array}$ & $\begin{array}{c}\text { Spillover } \\
\text { Reading } \\
\text { Times }\end{array}$ & Error Rate & $\begin{array}{c}\text { Paraphrase } \\
\text { Judgment Time }\end{array}$ \\
\hline Conventional, Fast & -0.281 & -0.363 & 9.00 & 4.37 \\
\hline Conventional, Slow & 0.260 & 0.137 & 13.00 & 4.17 \\
\hline Innovative, Fast & -0.053 & 0.179 & 12.00 & 4.77 \\
\hline Innovative, Slow & 0.089 & 0.059 & 8.00 & 4.14 \\
\hline
\end{tabular}

Note-Fast and slow refer to reading times for the conventional uses. Reading times were normalized for each subject. Error rates are the percentage out of 100 responses.

sure added to this the time taken to read the segment immediately following the target segment (for the nine items [45\%] for which the target segment was not the final unit of the sentence) to look for a spillover of processing beyond the target segment (the spillover measure).

Because the participants read short segments of text, there were large individual differences in reading times. To eliminate some of the effect of this variation, I normalized the reading time scores for each subject on both the target and spillover measures. A mean and standard deviation were computed for each subject across the 20 (less errors) reading times. Each reading time was converted to a $z$ score, and the $z$ scores were used in subsequent analyses.

Unlike in Experiments 1 and 2, there was little evidence that the innovative uses of the compound nouns took longer to understand than the conventional uses. For the target measure (conventional $=-0.016$, innovative $=$ 0.020 ), the $F$ values contrasting the reading times for the two types of uses were both less than 1 . For the spillover measure (conventional $=-0.12$, innovative $=0.12$ ), both component analyses fell in the range of marginal significance [subjects, $F(1,16)=4.13, M S_{\mathrm{e}}=0.11, p=$ .059 ; items, $\left.F(1,19)=3.82, M S_{\mathrm{e}}=0.33, p=.066\right]$. These results call the error recovery model into question even without the within-pair comparison.

Table 10 presents the pattern of data within pairs. The same rearrangement into fast and slow that was performed in Experiments 1 and 2 was again carried out. (Note, once again, that the critical statistical analyses do not avail themselves of this rearrangement.) The table presents normalized reading times for both measures, as well as the error rates and paraphrase times from the spillover analysis.

The statistical evidence lends weight to the conclusions of those experiments. Once again, the null hypothesis, based on the error recovery model, is that the difference in conventional reading times would be paralleled by the difference in innovative reading times. This hypothesis can be refuted by the target measure $\left[\min F^{\prime}(1,35)=3.35\right.$, $p=.076 ;$ subjects, $F(1,19)=9.33, M S_{\mathrm{e}}=0.56$, $p<.007$; items, $F(1,19)=5.22, M S_{\mathrm{e}}=0.64, p=.034$ ] and is strongly rejected by the spillover measure $\left[\min F^{\prime}(1,36)=4.24, p<.05\right]$.

The data in Table 10 suggest that the increased difference in slope from the target to the spillover measure arises predominantly from an increase in the time readers took to understand the preempting innovations based on the fast conventional compound nouns. Although the pattern of reading times for the fast and slow conventional uses and the slow innovative uses stays nearly constant, the fast innovative uses take relatively much longer. Taken alone, this increase suggests that an error recovery account should be given of the moment-by-moment processing. The claim could be made that readers request the next segment as soon as they have accessed the conventional meaning of a word from the lexicon. For the preempting innovations, this would have the consequence that construction of the appropriate meaning would not begin until the reader was already processing the next segment. Hence, the spillover effect for fast innovations. This account, however, makes it difficult to explain why spillover was not also found for the slow innovations. There is no evidence that the processing of the slow innovations was completed beyond the target boundary. The fast and slow innovations are differentiated only with respect to the conventional uses. An explanation that suggests interactions among the two kinds of uses-namely the concurrent processing model-seems more able to explain the results. The processing load caused by simultaneous activity for the fast preempting innovations might be sufficient to induce readers briefly to abandon the immediacy strategy.

The elaborated version of the concurrent processing model incorporating resource limitations finds limited support in these data. As is evident in Table 10, no strong negative relationship was found between the conventional and innovative differences (all sign tests and $t$ values were nonsignificant). Nonetheless, the pattern of data is consistent with the results of Experiments 1 and 2. Fast conventional reading times led to lengthy innovative reading times; slow conventional times led to comparable innovative reading times. Although, again, there are no reliable differences, this conclusion is echoed by the pattern of errors and paraphrase times. These moment-by-moment data are consistent with the elaborated concurrent processing model.

\section{GENERAL DISCUSSION}

In everyday language use, listeners and readers regularly recover new meanings for old words. The present 
experiments were concerned with the time course of this process. Two models were contrasted: The error recovery model, which assumes that sense creation operates only after sense selection fails, and the concurrent processing model, which suggests that sense selection and sense creation operate simultaneously. Preempting innovations provided the means to contrast the models.

The experiments suggested that the error recovery model is inadequate to explain comprehension of preempting compound nouns and agentives. Reading times for innovative sentences did not mirror those for conventional sentences. The general pattern was that the comprehension of the innovative compounds was (conservatively) independent of or (liberally) in competition with the comprehension of the conventional compounds. Furthermore, in Experiments 1 and 4, reading times for certain of the target sentences were identical whether the compound noun was being used innovatively or conventionally. For example, readers took roughly the same amount of time to understand "The horse race is the more popular event" when horse race meant "a race on horse" as when it meant "a race the length of King Louis's horse." Although some caution is necessary because the sentences occurred in different story contexts, this overlap suggests that error recovery could not be operating. Instead, the readers were creating and selecting meanings at the same time.

We might be concerned that the experimental setting-in which preempting innovations appeared at a much greater frequency than in normal discourse-brought about this result. Subjects were, in fact, quickly aware that some (25\% to $33 \%$ in actuality) of the stories contained unusual meanings. In these experiments, participants who strategically primed themselves to look for novel meanings could be particularly swift and accurate. However, the inversion of reading times, found most strongly in Experiment 1 , argues against this interpretation. It is hard to imagine why a reader operating under a "be ready for a novel meaning" strategy would be benefited only for sentences in which conventional understanding was slow; that is, if the reader did work with an expectation such as "because this story has been about two races, any compound about a race will refer to one of those two," any benefit should accrue to both horse race and foot race, which was not the case. The pattern of reading time suggests the regular operation of a process such as meaning creation, rather than momentary strategy induction.

The concurrent processing model has been given only the barest instantiation. The experiments support the notion that meaning creation goes on alongside meaning selection, but say little about the time course at a more refined level. A number of techniques have been developed to examine the precise time course of sense selection (see, e.g., Marslen-Wilson \& Tyler, 1980; Seidenberg et al., 1982; Simpson, 1981; Simpson \& Burgess, 1985; Swinney, 1979; Whitney, McKay, Kellas, \& Emerson, 1985). These techniques could potentially be used to map out the more precise time course of meaning cre- ation. For example, the availability of information relevant to the conventional and innovative meanings of preempting innovations could be tracked over time. Successful application of these techniques would provide more information about the processes that have been characterized broadly as concurrent

Similarly, we must clarify the components of the process of meaning creation. The current experiments suggest only that creation and selection coexist. They do not specify how comprehenders actually create meanings. For sense selection, most theorists believe that general world knowledge-embodied in schemas, scripts, frames, and the like (see Minsky, 1975; Rumelhart, 1980; Rumelhart \& Ortony, 1977; Schank \& Abelson, 1977)—drives comprehension. For sense creation, the information necessary to comprehension is often not part of general world knowledge. Instead, knowledge shared between individuals or well-defined communities comes into play (H. H. Clark \& Carlson, 1981). In the current experiments, readers were required to use information about idiosyncratic situations (a race the length of a King's foot; a pond in the shape of a fish) that they shared with an unknown writer to interpret contextual expressions. The exposition of the process of sense creation will depend heavily on a complete account of how comprehenders access and deploy appropriate, idiosyncratic mutual knowledge in the course of understanding.

Comprehenders are continually required to create new meanings for old words. Besides a variety of contextual expressions, they must interpret novel metaphors ("The old woman's face was marked by the furrows of time"), unusual referring phrases ("Ms. 'We're not out of the woods yet' is coming for dinner tonight"), innovative insults ("He's had his neurons knitted"), and a host of others. The current experiments suggest that meaning creation operates as a normal part of moment-by-moment comprehension: The language processing system is primed to accommodate a range of creative phenomena. Because listeners and readers are well-prepared, speakers and writers can use their language with maximal flexibility.

\section{REFERENCES}

aaronson, D. \& Scarborough, H. S. (1976). Performance theories for sentence coding: Some quantitative evidence. Journal of Experimental Psychology: Human Perception \& Performance, 2, 56-70. aAronson, D., \& SCARborough, H. S. (1977). Performance theories for sentence coding: Some quantitative models. Journal of Verbal Learning \& Verbal Behavior, 16, 277-303.

Clark, E. V. (1981). Lexical innovations: How children learn to create new words. In W. Deutsch (Ed.), The child's construction of language (pp. 299-328). London: Academic Press.

ClARK, E. V. (1982). The young word-maker: A case study of innovation in the child's lexicon. In E. Wanner \& L. R. Gleitman (Eds.), Language acquisition: The state of the an (pp. 390-425). Cambridge: Cambridge University Press.

Clark, E. V., \& Clark, H. H. (1979). When nouns surface as verbs Language, 55, 767-811.

ClaAk, E. V., \& HeChT, B. F. (1982). Learning to coin agent and instrument nouns. Cognition, 12, 1-24 
ClaRk, H. H. (1983). Making sense of nonce sense. In G. B. Flores d'Arcais \& R. Jarvella (Eds.), The process of understanding language (pp. 297-331). New York: Wiley.

Clark, H. H., \& Carlson, T. B. (1981). Context for comprehension In J. Long \& A. Baddeley (Eds.), Attention and performance IX (pp. 313-330). Hillsdale, NJ: Erlbaum.

Clark, H. H., \&errig, R. J. (1983). Understanding old words with new meanings. Journal of Verbal Learning \& Verbal Behavior, 22 591-608.

Ehrlich, K., \&ayner, K. (1983). Pronoun assignment and semantic integration during reading: Eye movements and immediacy of processing. Journal of Verbal Leaming \& Verbal Behavior, 22, 75-87.

FORSTER, K. I. (1976). Accessing the mental lexicon. In R. J. Wales \& E. C. T. Walker (Eds.), New approaches to language mechanisms (pp. 257-287). Amsterdam: North Holland.

ForSTER, K. I. (1979). Levels of processing and the structure of the language processor. In W. E. Cooper \& E. C. T. Walker (Eds.), Sentence processing: Psycholinguistic studies presented to Merrill Garrett (pp. 27-85). Hillsdale, NJ: Erlbaum.

Gerrig, R. J., \& Healy, A. F. (1983). Dual processes in metaphor understanding: Comprehension and appreciation. Journal of Experimental Psychology: Learning, Memory, \& Cognition, 9, 667-675.

GirBs, R. (1980). Spilling the beans on understanding and memory for idioms in conversation. Memory \& Cognition, 8, 149-156.

Gibss, R. (1984). Literal meaning and psychological theory. Cognitive Science, 8, 275-304

Grice, H. P. (1975). Logic and conversation. In P. Cole \& J. L. Morgan (Eds.), Syntax and semantics: Vol. 3. Speech acts (pp. 41-58). New York: Academic Press.

Grice, H. P. (1978). Further notes on logic and conversation. In P. Cole (Ed.), Syntax and semantics: Vol. 9. Pragmatics (pp. 113-128). New York: Academic Press.

Just, M. A., CARPenter, P. A., \& WoOlley, J. D. (1982). Paradigms and processes in reading comprehension. Journal of Experimental Psychology: General, 111, 228-238.

Kahneman, D. (1973). Attention and effort. Englewood Cliffs, NJ: Prentice-Hall.

MacWhinney, B., Bates, E., \& KLIEgl, R. (1984). Cue validity and sentence interpretation in English, German, and Italian. Journal of Verbal Leaming \& Verbal Behavior, 23, 127-150.

MacWhinney, B., Pleh, C., \& Bates, E. (1985). The development of sentence interpretation in Hungarian. Cognitive Psychology, 17, 178-209.

Marslen-Wilson, W. D., \& Tyler, L. K. (1980). The temporal structure of spoken language understanding. Cognition, 8, 1-71.

Minsky, M. (1975). A framework for representing knowledge. In P. H. Winston (Ed.), The psychology of computer vision (pp. 211-277). New York: McGraw-Hill.

Mitchell, D. C., \& Green, D. W. (1978). The effects of context and content on immediate processing in reading. Quarterly Journal of Experimental Psychology, 30, 609-636.

Norman, D. A., \& Bobrow, D. G. (1975). On data limited and resource limited processes. Cognitive Psychology, 7, 44-64.

NunberG, G. (1979). The non-uniqueness of semantic solutions. Polysemy. Linguistics \& Philosophy, 3, 143-184.

Ortony, A., Schallert, D. L., Reynolds, R. E., \& ANTos, S. J. (1978). Interpreting metaphors and idioms: Some effects of context on comprehension. Journal of Verbal Learning \& Verbal Behavior, 17, 465-477.

Posner, M. I., \& BoIES, S. J. (1971). Components of attention. Psychological Review, 78, 391-408.

Rumelhart, D. E. (1980). Schemata: The building blocks of cognition. In R. J. Spiro, B. C. Bruce, \& W. F. Brewer (Eds.), Theoretical issues in reading comprehension: Perspectives from cognitive psychology, linguistics, artificial intelligence, and education (pp. 33-58). Hillsdale, NJ: Erlbaum.

Rumelhart, D. E., \& Ortony, A. (1977). The representation of knowledge in memory. In R. C. Anderson, R. J. Spiro, \& W. E. Montague (Eds.), Schooling and the aquisition of knowledge (pp. 99135). Hillsdale, NJ: Erlbaum.
SCHANK, R., \& ABELSON, R. F. (1977). Scripts, plans, goals, and understanding. Hillsdale, NJ: Erlbaum.

SEARLE, J. R. (1975). Indirect speech acts. In P. Cole \& J. L. Morgan (Eds.), Syntax and semantics: Vol. 3. Speech acts (pp. 59-82). New York: Academic Press.

SeARle, J. R. (1979). Metaphor. In A. Ortony (Ed.), Metaphor and thought (pp. 92-123). Cambridge: Cambridge University Press.

Seidenberg, M. S., Tanenhaus, M. K., Leiman, J. M., \& BIENKOWSKI, M. (1982). Automatic access of the meanings of ambiguous words in context: Some limitations of knowledge-based processing. Cognitive Psychology, 14, 489-537.

Simpson, G. B. (1981). Meaning dominance and semantic context in the processing of lexical ambiguity. Journal of Verbal Learning \& Verbal Behavior, 20, 120-136.

Simpson, G. B., \& Burgess, C. (1985). Activation and selection processes in the recognition of ambiguous words. Journal of $E x$ perimental Psychology: Human Perception \& Performance, 11, 28-39.

STERNBERG, S. (1966). High-speed scanning in human memory. Science, $153,652-654$.

SternberG, S. (1969). Memory-scanning: Mental processes revealed by reaction-time experiments. American Scientist, 57, 421-457.

SWINNEY, D. A. (1979). Lexical access during sentence comprehension: (Re)consideration of context effects. Journal of Verbal Leaming \& Verbal Behavior, 18, 645-659.

SWInNey, D. A., \& CuTler, A. (1979). The access and processing of idiomatic expressions. Journal of Verbal Learning \& Verbal Behavior, 18, 523-534.

Thibadeau, R., Just, M. A., \& Carpenter, P. A. (1982). A model of the time course and content of reading. Cognitive Science, 6, 157-203.

Whitney, P., McKay, T., Kellas, G., \& Emerson, W. A., JR. (1985). Semantic activation of noun concepts in context. Journal of Experimental Psychology: Learning, Memory, \& Cognition, 11, 126-135.

\section{NOTE}

1. This control was suggested by Alice F. Healy.

\section{APPENDIX}

\section{Preempting Innovations}

Example (Interpretation; Source)

1. "I'm going to talk about my three year old study." (Developmental study with subjects who are three years old; Conversation)

2a. "Are you watering?"' (Going to get a glass of water; Conversation)

2b. "I am yoghurting and watering." (Reply)

3. "One of my housemates ... foiled the potatoes." (Wrapped the potatoes in foil; Conversation)

4. "The two finalists had competed once before." (Two teams of finalists [four people]; Conversation)

5. "I think I'm running fast." (Watch is running fast; Conversation)

6. "You didn't even fold this basket." (Basket of laundered clothing; Conversation)

7. "I' $m$ being persecuted by these ascots. (Students wearing ascots; Conversation)

8. "The terminal facilities just aren't there." (The ability to terminate conversations; Conversation)

9. "I run in the ghetto streets." (Faculty ghetto; Conversation)

10. "Let me give you your orange juice." (Coupon for free orange juice; Conversation)

11. "These are the model subjects." (Subjects trained on a mental model; Psychology seminar) 
12. "[Under those conditions] you get unexpected reaction times." (Reaction times to unexpected events; Psychology seminar)

13. "We don't want to say that there's no evidence of streaking." (Basketball players having hot streaks in shooting; Psychology seminar)

14. "If the restaurant has a schema for paying, then ..." (Script of stereotypical restaurant events; Psychology seminar)

15. "They have blind raters looking at the film." (Raters who are blind to the experimental design; Psychology seminar)

16. "The third was a control question." (A question about control; Psychology seminar)

17. "We only used the data when our subject - whether actor or gymnast-was correct." (Facial gymnast, someone who was well-trained in moving facial muscles; Psychology seminar)

18a. "There are 20,000 uniforms in this city." (People wearing uniforms [uniformed police officers]; Television program)

$18 \mathrm{~b}$. "The uniforms just approved their new contract." (Television program)

18c. "Send him home with a couple of uniforms." (Television program)

19. "[How can they] cut off a man's legs?" (The legs of a man's desk; Television program)

20. "You should avoid marrying a sheep at all costs." (Someone born in the Year of the Sheep; Television program)

21. "[Mommy's] in the bedroom coloring. (Coloring her hair; Television program)

22. "The people who get second choice in the draft-my old team the Indiana Pacers." (The team he rooted for; Television program)

23. "Rabbit ... plucks the pack of cigarettes from his bobbing shirt pocket, and without breaking stride cans it in somebody's open barrel." (Throws it in the can; John Updike, Rabbit Run)
24. "In the big room of the Verity Press, ceilinged with fluorescent tubes ..." (Lights are attached to the ceiling; John Updike, Rabbit Redux)

25. "The dead green bleeds slowly." (Green turtle; Peter Mathiessen, Far Tortuga)

26a. "A good-natured, superior murmur passed over the potato salad.' (People eating potato salad; Thomas McGuane, The Bushwhacked Piano)

26b. "The potato salad had begun to stir."

26c. "[T]he potato salad began to advance upon the podium."

27. "That ... head ... weaving imperceptibly from side to side, almost like that of a woman heading a load of canes down a slope." (Balancing on her head; Paule Marshall, The Chosen Place, The Timeless People)

28. "She crowned me, that girl did. No matter what went wrong or how tired I was, she was my crown." (Crowning achievement; Toni Morrison, Tar Baby)

29. "Farragut was afraid that the beard would return ..." (A man with a beard; John Cheever, Falconer)

30. "I pitied her ... It was a feeling ... worse than being forked.' (Stabbed through the hand with a fork; Louise Erdich, short story)

31. "'Please supply serial number of stolen implement to facilitate reporting of offense,' the beachball brayed." (The beachball-shaped robot; Jeffry Scott, short story)

32. "The brown suit twitched." (The man in the brown suit; Irwin Shaw, short story)

33. "As even Tommy says, adults do not tell eights very much ..." (Eight-year-old children; Newspaper book review)

34. "Mills High track standout runs 400 hurdles in 56.08." (400-meter race; Newspaper headline)

35. "Astronauts plan to orbit experiment rack today." (To put into orbit; Newspaper headline)

(Manuscript received February 9, 1987; revision accepted for publication July 18, 1988.) 